American Journal of Biochemistry and Biotechnology, 2 (4): 161-169, 2006

ISSN 1553-3468

(c) 2006 Science Publications

\title{
Mapping QTLs Linked to Physio-Morphological and Plant Production Traits under Drought Stress in Rice (Oryza sativa L.) in the Target Environment
}

\author{
S. Michael Gomez, S. Satheesh Kumar, P. Jeyaprakash, R. Suresh, K. R. Biji \\ N. Manikanda Boopathi, Adam H. Price and R. Chandra Babu \\ Centre for Plant Molecular Biology, TNAU, Coimbatore-641003, India
}

\begin{abstract}
Drought stress is a major constraint for rice (Oryza sativa L.) production and yield stability in rainfed ecosystems. Identifying genomic regions (QTLs) contributing in drought resistance will help to develop rice cultivars suitable for water-limiting environments through marker-assisted breeding. QTLs linked to physio-morphological and plant production traits under drought stress in the field were mapped by evaluating $177 \mathrm{~F}_{6}$ recombinant inbred (RI) lines of Bala $\times$ Azucena under rainfed conditions in the target environment (TE). The rice lines were subjected to severe drought stress during reproductive phase due to a natural rainfall failure event. The RI lines showed significant variation in physio-morphological and plant production traits under stress. A total of 24 QTLs were identified for various traits under stress, which individually explained 4.6 to $22.3 \%$ phenotypic variation. Composite interval mapping detected three markers viz., RM3894, RG409 and G1073 on chromosomes 3 and 8 linked to grain yield under drought stress in TE, respectively explaining $22 . .3,17.1$ and $10.9 \%$ of phenotypic variation. QTLs for leaf drying, days to $50 \%$ flowering and number of productive tillers under drought stress co-located at certain of these regions. Further, QTLs for several root traits overlapped with QTLs for grain yield under stress in these RI lines, indicating the pleiotropic effects of root trait QTLs on rice performance under stress. Correlation coefficients between potential root traits determined in another study and plant production under stress in this study were not significant in these RI lines. Consistent QTLs for drought resistance traits and yield under drought stress in TE were detected and might be useful for rainfed rice improvement.
\end{abstract}

Key words: Rice, drought QTL, target environment, physio-morphological traits, marker assisted breeding

\section{INTRODUCTION}

Rice $^{[1]}$ (Oryza sativa), one of the important food crops, is grown on 154 million hectares world-wide in a wide range of environments ${ }^{[1]}$. About $45 \%$ of the world's rice is cultivated in rainfed ecosystems ${ }^{[2]}$. These areas often experience severe water deficits due to low and uneven rainfall distribution patterns and yields are largely reduced by drought. Drought stress is a serious limiting factor to rice production and yield stability in rainfed areas and 18 million tons of rice valued at US\$ 3600 millions is lost annually to drought ${ }^{[3]}$. Development of drought resistant cultivars will considerably improve rainfed rice production. However, little progress has been made in improving the genetic potential of rice for drought resistance because lack of phenotyping facilities to precisely screen large germplasm for drought resistance, inherent variation in the field and only one experimentally droughted crop per year ${ }^{[4,}{ }^{5}$. Alternatively, yield improvements in water-limited environments can be achieved by selecting for secondary traits contributing to drought resistance in breeding programs. The effectiveness of selection for secondary traits to improve yield under water limiting conditions has been demonstrated in maize ${ }^{[6]}$, wheat ${ }^{[7]}$ and sorghum ${ }^{[8]}$. Several putative traits contributing in drought resistance in rice have been documented ${ }^{[9,10]}$. Since phenotypic selection for these traits involves complex, labourintensive protocols and cost demanding experimental conditions these traits are rarely selected for in crop improvement programs. An ideal secondary trait should be easy to measure, highly heritable, genetically correlated with grain yield under stress and should show genetic variation in the target species ${ }^{[11]}$. Molecular tools facilitate the identification of genomic locations linked to traits of interest and help in indirect selection of such complex traits without the need for difficult phenotypic measurements. Quantitative trait loci (QTLs) have been identified for several drought resistance component traits in rice ${ }^{[12-21]}$. Although these results indicated the map positions of QTLs associated with drought resistance traits, effects of those traits on plant production under drought has not yet been established. Thus there is a need to determine whether the QTLs linked to drought resistance traits also impact yield under stress in field conditions. By comparing the coincidence of QTLs for specific traits and QTLs for

Corresponding Author: $\quad$ Dr. R. Chandra Babu, Centre for Plant Molecular Biology, TNAU, Coimbatore-641003, India 
plant production under drought, it is possible to test whether a particular constitutive or adaptive response to drought stress is of significance in improving field level drought resistance ${ }^{[22]}$. Previous studies from this laboratory indicated overlapping of QTLs for root traits with those of yield under managed water stress conditions in rice ${ }^{[23]}$. However, only a few QTLs associated with grain yield under drought stress in field conditions have so far been identified in rice ${ }^{[23-25]}$. QTLs linked to yield under drought stress, especially in the target environment (TE) have not yet been identified in rice. Thus, RI lines of Bala $\times$ Azucena were used in this study to identify QTLs linked to rice plant performance under drought stress in TE. The specific objectives of the study were (i) to identify genomic regions linked to physio-morphological and plant production traits under drought stress in the field at TE, (ii) to establish the nature of phenotypic and genetic association between physio-morphological traits and field performance and (iii) to identify potential QTLs for drought resistance improvement using marker-assisted selection (MAS) in rice.

\section{MATERIALS AND METHODS}

Plant material: Bala is an upland-adapted semi-dwarf indica cultivar from eastern India. It is noted for early maturity and fairly good level of drought tolerance ${ }^{[26]}$. It has short and thin roots. Azucena is a traditional upland japonica cultivar from the Philippines. It has comparatively thick and deep roots ${ }^{[27]}$ and low but stable yields under mild drought stress in upland conditions $^{[26]}$. These two cultivars respond quite differently to drought stress ${ }^{[28]}$. A sub set of $177 \mathrm{~F}_{6} \mathrm{RI}$ lines of Bala $\times$ Azucena were used in the present study to map QTLs linked to physio-morphological and plant production traits under drought stress in TE.

Field experiment: The 177 RI lines along with their parents were evaluated under rainfed upland condition in experimental fields of the Agricultural Research Station, Paramakudi, located in TE during September, 2003 - February, 2004 wet season. Hand sowing of seeds@100 kg ha ${ }^{-1}$ was done in dry soil before monsoon on September 13, 2003 in $2.0 \times 0.2 \mathrm{~m}^{2}$ size plots with $20 \times 10 \mathrm{~cm}$ spacing between and within rows, respectively. The RI lines were replicated three times each under irrigated control and rainfed treatments adopting a completely randomized block design. NPK fertilizers were applied @ 50:25:25 kg ha${ }^{1}$, respectively. While P and farm yard manure (@12.5 $\mathrm{t} \mathrm{ha}^{-1}$ ) were applied in full basally at the time of sowing, $\mathrm{N}$ and $\mathrm{K}$ were applied in two splits as top dressing. Paddy micronutrient mixture was applied @ $12.5 \mathrm{~kg} \mathrm{ha}^{-}$ 1 on $39^{\text {th }}$ day after sowing (DAS). Insect and weed control measures were applied periodically as required.
Field measurements: There was $26 \mathrm{~mm}$ of rain during the week of September 27 - October 3, 2003 using which seeds germinated and seedlings established. Following this, there was a total of $186 \mathrm{~mm}$ of rain fall until 58 days after emergence (DAE) of seedlings. After this, there was complete cessation of rains and there was a continuous rainless period of 58 days starting from $60 \mathrm{DAE}$ to harvest. Data on leaf rolling, leaf drying, canopy temperature and leaf chlorophyll were recorded in rainfed plots $28^{\text {th }}$ day after last rainfall coinciding with flowering and the early grain filling stage (86 DAE). Leaf rolling and drying scores were made midday using 1-7 scale standardized for rice ${ }^{[29]}$. Canopy temperature was measured using a hand-held infrared thermometer (Model AG-42, Telatemp Corporation Inc., Fullerton, USA) as described by Garrity and O'Toole ${ }^{[30]}$. Chlorophyll was recorded in the top most fully expanded leaf using soil plant analysis development (SPAD) meter (SPAD-502, Minolta Corp., USA). Data on days to $50 \%$ flowering was recorded as and when $50 \%$ of the plants in each RI line flowered. Further, data on plant height, panicle length, number of productive tillers, straw and grain yields $\left(\mathrm{g} \mathrm{m}^{-2}\right)$ were recorded at harvest. Previously, a subset of 140 of these RI lines and their parents were grown in thin soil chambers under two treatment conditions and screened for root morphological and distribution traits twice during 1997 and 1998 under green house condition in Bangor, North Wales, UK by Price et $a{ }^{[31]}$. Briefly, the two treatment conditions included: a long term, early water-deficit which started with fully saturated soil but received no more water (WD0) and a well-watered treatment in which water was withheld after day 49 (WD49) (during the final, eighth week of the experiment). Root morphological traits viz., root - shoot ratio, deep root weight, basal root thickness, maximum root length and number of roots past $100 \mathrm{~cm}$ depth were recorded. Data for potential root traits from the WD49 treatment were used to find out the correlations with various physio-morphological and plant production traits under stress in TE of the present study.

Statistical analysis: Analysis of variance was done using the general linear model (GLM) procedure of the statistical analysis software (SAS) program $^{[32]}$ in order to check the genetic variance among the RI lines for all the traits. The frequency distribution of all the traits was tested for skewness. From the covariance values, the broad sense heritability $(\mathrm{H})$ was calculated for each trait using the formula,

$H=\sigma_{\mathrm{G}}^{2} /\left(\sigma^{2}{ }_{\mathrm{G}}+\sigma^{2} \mathrm{e} / \mathrm{k}\right)$

Where, $\sigma_{G}^{2}$ and $\sigma_{e}^{2}$ were the genetic and residual variances, respectively and ' $\mathrm{k}$ ' the number of replications. Phenotypic correlations among the traits were computed using the trait mean values.

Linkage map and QTL analysis: The genotypic data of the 177 RI lines were used to map QTLs linked 
to various traits determined in the present study. The genetic linkage map consisted of 163 marker loci including 102 restriction fragment length polymorphisms (RFLPs), 26 amplified fragment length polymorphisms (AFLPs), 23 microsatellite markers and 12 bacterial artificial chromosome (BAC) clone markers (developed from data published by Shen et $a{ }^{[33]}$ ) on 13 linkage groups with a total map length of 1720 centiMorgan $(\mathrm{cM})^{[17,31]}$. Composite interval mapping was conducted using QTL cartographer version $1.15^{[34]}$. Permutation testing (using QTL cartographer) on some of this data indicated that a logarithm of the odds ratio (LOD) score of 3.3 is suitable as the genome wide 5\% significance threshold for this set of data ${ }^{[31]}$. However, putative QTLs with LOD 2.5-3.2 are also included.

\section{RESULTS AND DISCUSSION}

Variation in physio-morphological and plant production traits under stress: The year 2003 was a very severe drought year in India, including the TE used in this study. Due to the extreme drought condition the irrigation well in the experiment station did not recharge and dried up and the control treatment plots could not be irrigated. Hence the RI lines in all the six replications remained wholly rainfed from sowing to harvest. Thus the RI lines were subjected to severe but natural drought stress in this experiment. Rice plants received only a total of $212 \mathrm{~mm}$ rain during the entire cropping period of 120 days as against the long-term (25 years) average of $475 \mathrm{~mm}$ for this season at this site. This $212 \mathrm{~mm}$ of rainfall was received from sowing up to $58 \mathrm{DAE}$ and after this there was no rainfall until harvest. There was a continuous rain free period of 58 days starting from 60 DAE of seedlings up to maturity and thus the RI lines were subjected to severe water stress during the reproductive phase. Significant variation was noticed among the RI lines for drought response in terms of various water stress indicators, physio-morphological and plant production traits under drought stress in TE in this study (data not shown). Similar genotypic variation in physio-morphological and plant production traits under drought stress was reported earlier in these RI lines ${ }^{[26]}$ and several other rice lines from experiments conducted in managed stress environments (MSE) ${ }^{[23,24,35-39]}$ Leaf rolling score ranged from 1.0 - 5.7 with a mean of 2.6 across the RI lines. A similar degree of leaf rolling was reported in these RI lines under severe stress from field experiments conducted at West African Rice Development Association (WARDA), West Africa and International Rice Research Institute (IRRI), Philippines under $\mathrm{MSE}^{[40]}$. While Bala had a leaf rolling score of 4.3, Azucena did not have leaf rolling under stress at the time of observation in this study. This is in contrast to previous findings under laboratory conditions using detached leaves, wherein Azucena rolled its leaves faster than Bala upon excision ${ }^{[41]}$. At the whole plant level in field conditions, the deep rooting habit of Azucena might have helped its leaves remain turgid longer, while Bala with its comparatively shallow roots might have lost turgor and its leaves rolled earlier than Azucena. The result emphasizes the importance of understanding whole plant physiology in terms of drought tolerance in the field environment. Leaf drying ranged from $1.0-4.3$ with a mean of 1.8 across the RI lines under stress. Similar variation and range of leaf drying were earlier reported in these RI lines under drought stress in $\mathrm{MSE}^{[26,38]}$. However, there was no significant difference in leaf drying between Bala (2.3) and Azucena (1.7) under stress in this study. Though Bala had faster leaf rolling under stress in this study, its leaves had higher stomatal resistance upon excision $^{[41]}$ and this might have helped its leaves avoid desiccation. Canopy temperature ranged from 26.9 $38.4^{\circ} \mathrm{C}$ with a mean of $32.0^{\circ} \mathrm{C}$ across the RI lines under stress. Similar variation in canopy temperature was reported among rice lines under water stress from field experiments in $\mathrm{MSE}^{[23,39]}$. There was no significant difference in canopy temperature between Bala and Azucena, 27.4 and $29.3^{\circ} \mathrm{C}$, respectively. Leaf chlorophyll content ranged from 29.4 - 52.3 with a mean of 39.8 across the RI lines under stress. However, there was no significant difference in leaf chlorophyll under stress between Bala and Azucena, with SPAD values of 42.7 and 40.7 , respectively. Days to $50 \%$ flowering varied from 54-90 with a mean of 75 DAE across the RI lines. While Bala had 50\% flowering 71 DAE, Azucena did not flower by the time of harvest. Similar variation in flowering among these RI lines were reported from MSE and Azucena was found to have delayed flowering as compared to Bala under stress $^{[26]}$. The RI lines showed considerable variation in plant production traits under stress in terms of plant height, number of productive tillers, panicle length, straw and grain yields. Azucena was taller and produced more straw yield under stress than Bala. Similar variation in plant production traits under water stress was earlier reported in these RI lines in MSE $^{[26,38]}$. Transgressive segregation in both directions was observed for most traits indicating that both parents contributed favourable alleles for these traits. For the traits viz., plant height, panicle length, grain yield, leaf drying, leaf rolling and straw yield under stress, the majority of the favourable alleles came from the japonica ecotype, Azucena. The accession, Bala contributed favourable alleles for days to $50 \%$ flowering under stress. Both parents contributing positive alleles for various physio-morphological and plant production traits under stress were reported earlier in several rice populations ${ }^{[15,16,19-21,23,24,37,42]}$. The frequency distribution of phenotypes for most traits evaluated in this study approximately fitted normal distribution. The broad-sense heritabilities were relatively high for most traits except grain yield under 
drought stress in TE. Low to moderate heritability of yield under stress has been reported earlier in these RI lines from experiments conducted in MSE and is considered a limitation in breeding for drought resistance in crops ${ }^{[26]}$. High heritability was observed for leaf rolling, leaf drying, canopy temperature and leaf chlorophyll content under stress indicating the preponderance of additive gene action on these traits. Therefore, direct selection based on these traits may be helpful to improve drought resistance in rice.

Correlation among physio-morphological and plant production traits under stress: The phenotypic correlations among traits showed that parameters of water stress indicators were correlated with plant production traits under stress. Leaf rolling and drying scores were negatively correlated with leaf chlorophyll and straw yield, while leaf rolling was negatively correlated with grain yield under stress. Leaf chlorophyll had significant negative correlation with canopy temperature $(\mathrm{r}=-0.432 * *)$ under stress. Leaf rolling and leaf drying showed significant negative correlations with straw yield $(\mathrm{r}=-0.386 * *$ and $0.381^{* *}$, respectively). Similar relationships among water stress indicators and plant production traits were reported earlier in these RI lines ${ }^{[26]}$ and also in other rice lines in $\mathrm{MSE}^{[23,24,35]}$. Pantuwan et al. ${ }^{[43]}$ observed negative association of leaf rolling and leaf drying with grain yield under stress. Leaf chlorophyll had significant positive correlation with straw and grain yields under stress. Lafitte et $a l .{ }^{[26]}$ reported that chlorophyll content appeared to be a promising secondary trait because it showed a high genetic correlation with yield under stress; it could be measured early in the season and it had high heritability. Panicle length and number of productive tillers had significant positive correlations with grain yield under stress.

QTLs linked to physio-morphological and plant production traits under drought stress in TE: Results of composite interval mapping and the summary statistics for all significant QTLs are given (Table 1). A total of 24 QTLs were identified for various physiomorphological and plant production traits under drought stress in this study, which individually explained 4.6 to $22.3 \%$ of the phenotypic variation. The number of QTLs per trait under stress were: 5 for leaf rolling, 4 for leaf drying, 3 for days to $50 \%$ flowering, 5 for plant height, 2 for number of productive tillers, 1 for panicle length, 3 for grain yield and 1 for straw yield (Table 1). No QTL was identified for canopy temperature and leaf chlorophyll under stress in this study. The grain yield QTL at RG409 on chromosome 3 explained the highest proportion of phenotypic variation (22.3\%). QTLs linked to various plant production traits under drought stress in TE were located through out the genome except chromosomes 2, 7 and 10 . Overlapping of QTLs for different traits was observed in this study. For example, QTLs for grain yield, days to $50 \%$ flowering and leaf drying under stress were mapped to RM3894RG409 region on chromosome 3. Similar colocation of
3

8

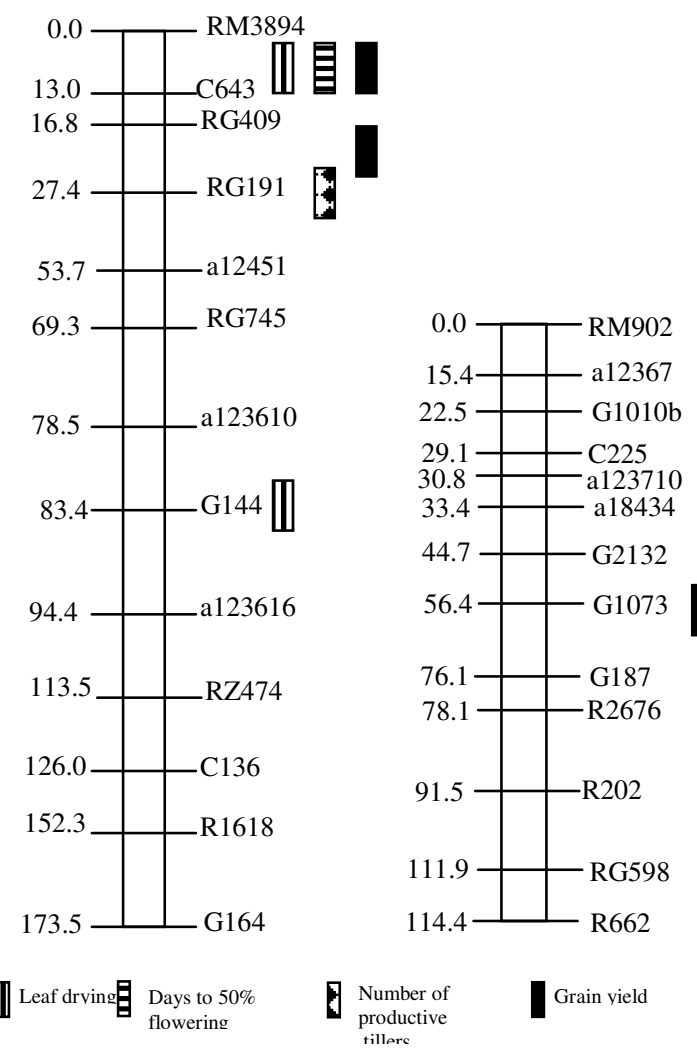

Fig. 1: Chromosomes $3 \& 8$ showing putative QTLs associated with physio-morphological and grain yield under drought stress in TE in Bala $\mathrm{x}$ Azucena RI lines based on composite interval mapping

QTLs for water stress indicators and plant production traits under stress was reported earlier in rice ref,24,37] $^{[2,}$ including these RI lines from MSE ${ }^{[26,40]}$.

Colocation of QTLs for drought resistance and plant production traits under stress: Identifying genomic regions influencing the response of yield and its components to water stress will aid in our understanding of the genetics of drought resistance and development of drought tolerant cultivars ${ }^{[24]}$. The ability of the root system to meet the evapotranspirational demand from deep soil moisture and osmotic adjustment were reported as major drought resistance traits in rice ${ }^{[10]}$. Although numerous QTLs associated with several drought resistance traits have been mapped in rice ${ }^{[12-17,19-21,44]}$, the effect of those traits on rice plant performance under water stress in the field condition is not well established. Among other reasons, information on genomic regions associated with grain yield and its components under drought stress in field condition is limited in rice. A few QTLs linked to yield under drought stress in MSE were reported earlier using IR $64 \times$ Azucena $^{[37]}$ and CT9993 $\times$ IR62266 $^{[23,24]}$ rice doubled haploid (DH) lines. Recently, Lafitte et al. ${ }^{[26]}$ identified 31 QTLs associated with rice growth and 
Table 1: QTLs detected for water stress indicators and plant production traits under drought stress in TE in Bala $\times$ Azucena RI lines using

\begin{tabular}{|c|c|c|c|c|c|c|c|}
\hline \multirow[b]{2}{*}{ Trait } & \multirow[b]{2}{*}{ Chromosome } & \multicolumn{2}{|l|}{ QTL position in $\mathrm{cM}$} & \multirow[b]{2}{*}{ LOD } & \multirow[b]{2}{*}{$\begin{array}{l}\mathrm{R}^{2} \\
(\%)\end{array}$} & \multirow[b]{2}{*}{$\begin{array}{l}\text { Additive } \\
\text { effect }\end{array}$} & \multirow[b]{2}{*}{$\begin{array}{l}\text { Donor } \\
\text { drought } \\
\text { resistance QTL }\end{array}$} \\
\hline & & $\begin{array}{l}\text { Above }(-) \text { below } \\
(+) \text { nearest marker }\end{array}$ & $\begin{array}{l}\text { From the } \\
\text { top of } \\
\text { linkage } \\
\text { group }\end{array}$ & & & & \\
\hline \multirow[t]{5}{*}{ Leaf rolling } & 5 & $\mathrm{R} 569+19.5$ & 57.5 & 2.7 & 7.4 & -0.305 & Azucena \\
\hline & 5 & C624+10.0 & 85.2 & 4.1 & 10.9 & 0.378 & Bala \\
\hline & 9 & P0463D04+1.9 & 65.6 & 3.5 & 7.6 & -0.307 & Azucena \\
\hline & 11 & $\mathrm{G} 320+6.0$ & 46.3 & 2.9 & 6.5 & -0.279 & Azucena \\
\hline & 11 & G1465 & 103.9 & 2.6 & 5.7 & 0.270 & Bala \\
\hline \multirow[t]{4}{*}{ Leaf drying } & 1 & $\mathrm{C} 178+16.0$ & 76.7 & 3.4 & 8.6 & 0.312 & Bala \\
\hline & 3 & C643 & 14.1 & 3.6 & 6.9 & -0.364 & Azucena \\
\hline & 3 & $\mathrm{G} 144+8$ & 91.4 & 3.7 & 9.1 & 0.317 & Bala \\
\hline & 11 & $\mathrm{RZ141+7.9}$ & 29.5 & 3.8 & 9.3 & -0.322 & Azucena \\
\hline \multirow[t]{3}{*}{ Days to $50 \%$ flowering } & 3 & M3894+14.0 & 14.0 & 3.4 & 7.8 & 2.476 & Bala \\
\hline & 4 & RG163+18.0 & 99.1 & 2.6 & 14.0 & 3.179 & Bala \\
\hline & 6 & $\mathrm{a} 12377+2.0$ & 127.1 & 3.2 & 7.9 & -2.467 & Azucena \\
\hline \multirow[t]{5}{*}{ Plant height $(\mathrm{cm})$} & 1 & RG532 & 0.0 & 3.1 & 5.3 & -0.141 & Bala \\
\hline & 1 & RM212+16.0 & 165.4 & 4.0 & 9.9 & 0.203 & Azucena \\
\hline & 4 & C734 & 23.8 & 2.8 & 4.6 & 0.149 & Azucena \\
\hline & 4 & RG163+6.0 & 87.1 & 4.5 & 11.2 & 0.205 & Azucena \\
\hline & 5 & $\mathrm{RZ70}$ & 87.9 & 4.6 & 7.8 & -0.173 & Bala \\
\hline \multirow[t]{2}{*}{ No. of productive tillers } & 1 & $\mathrm{C} 1370+2.0$ & 123.8 & 2.8 & 8.5 & 0.125 & Azucena \\
\hline & 3 & RG191+22.0 & 49.4 & 2.5 & 9.4 & -0.130 & Bala \\
\hline Panicle length $(\mathrm{cm})$ & 1 & $\mathrm{C} 86+14.0$ & 183.2 & 3.7 & 12.3 & 0.922 & Azucena \\
\hline \multirow[t]{3}{*}{ Grain yield $\left(\mathrm{g} / \mathrm{m}^{2}\right)$} & 3 & RM3894 +10.01 & 10.01 & 7.9 & 22.3 & -0.421 & Bala \\
\hline & 3 & $\mathrm{RG} 409+4$ & 20.85 & 5.7 & 17.1 & -0.363 & Bala \\
\hline & 8 & G1073-1 & 55.46 & 4.0 & 10.9 & 0.182 & Azucena \\
\hline Straw yield $\left(\mathrm{g} / \mathrm{m}^{2}\right)$ & 12 & a123614+9.6 & 75.6 & 2.5 & 6.6 & 0.641 & Azucena \\
\hline
\end{tabular}

yield traits in Bala $\times$ Azucena RI lines in MSE but no QTL was found for grain yield under stress. Moreover, no QTLs linked to yield under drought stress especially in TE have so far been reported in rice. Notably, the present study identified three QTLs linked to grain yield under natural drought stress in TE on chromosomes 3 and 8 explaining 10.9 to $22.3 \%$ phenotypic variation. Comparing the genomic locations, coincidence of QTLs for various drought resistance and plant production traits was noticed in these RI lines. For instance, the region RM3894-RG191 on chromosome 3 was associated with grain yield, days to $50 \%$ flowering and leaf drying under stress in this study. These traits were correlated phenotypically as well. The same region was linked to stomatal resistance $^{[41]}$, root penetration ability, root thickness, leaf drying, relative water content ${ }^{[17,31,40]}$, panicle length, tiller number $\mathrm{m}^{-2}$ and biomass under stress in $\mathrm{MSE}^{[26]}$ in these RI lines. Another QTL for grain yield under stress was identified on chromosome 8 (G1073) in this study. This region was associated with leaf drying and relative water content in these RI lines ${ }^{[40]}$. Similarly, colocation of QTLs for water stress indicators and plant production traits under stress with those of drought resistance component traits was also noticed in these RI lines. For instance, the QTL region C624 on chromosome 5 was identified for leaf rolling under stress in this study. In this region, QTLs for maximum root length, adventitious root thickness ${ }^{[14]}$, number of penetrated roots ${ }^{[17]}$, leaf rolling and relative water content under stress ${ }^{[40]}$ were earlier mapped in these RI lines. A QTL for leaf drying under water stress was identified near RZ141 marker on chromosome 11 in this study. In this region, a QTL for leaf drying was mapped in these RI lines earlier also ${ }^{[40]}$. Three QTLs were identified for days to $50 \%$ flowering under stress in this study. RG163 on chromosome 4 explained highest phenotypic variation $(14.0 \%)$. In this region, Price et al. ${ }^{[31]}$ located QTLs for root-shoot dry weight ratio and root weight in these RI lines.

Phenotypic correlations between root and plant production traits under stress: Results presented here indicate overlapping of QTLs for plant production traits under stress identified in this study at TE and QTLs for several root traits reported earlier ${ }^{[14,17,31,40]}$ in these RI lines. There may be genetic linkage or pleiotrophy between these traits. Phenotypic correlations were worked out between plant water stress indicators and production traits under stress from this study and potential (constitutive) root traits (as determined by Price et al., ${ }^{[31]}$ in a separate experiment) for these RI lines. Root traits showed no significant correlation with most of the physio-morphological and plant production traits in this study except plant height. Root traits had positive correlations with plant height under stress. Similar relation was reported earlier in rice ${ }^{[39]}$. Basal root thickness had significant negative correlation with days to $50 \%$ flowering under stress. Similar results were reported earlier in rice ${ }^{[23]}$. Most root traits showed no correlation with grain yield under stress except deep 
root dry weight which showed negative correlation with yield under stress $(\mathrm{r}=-0.230 *)$. Lafitte et al. ${ }^{[26]}$ also reported a negative correlation between root depth and spikelet fertility under stress in these RI lines. Zhang et $a l .{ }^{[45]}$ reported that root traits did not have any positive impact on plant production under drought stress in CT9993 $\times$ IR62266 DH lines in MSE. Ingram et al. ${ }^{[46]}$ also found no significant association between root length and grain yield under water stress in rice. However, positive associations between root thickness and grain yield under stress have been reported in rice $^{[23,39]}$. One of the reasons for the lack of positive impact of root traits on grain yield under stress in this study is that all the RI lines might not have undergone uniform and severe water stress, inspite of the low average grain yield of 0.06 tha $^{-1}$ across rice lines due to severe drought in this study. As mentioned by Pantuwan et al. ${ }^{[43]}$, a drought intensity that causes a $50 \%$ yield reduction is considered critical for the expression of drought tolerance mechanisms in rice. Uniform and severe drought stress will amplify the genetic difference between lines for drought tolerance $^{[11]}$. Days to $50 \%$ flowering ranged from 54 to 90 among the RI lines and the last rainfall event occurred 58 DAE in this study. Hence, early flowering RI lines might have completed yield formation before development of severe stress. This study confirmed the complexity of the associations between yield under stress and components of drought tolerance in rice ${ }^{[45]}$.

Consistency of QTLs across genetic backgrounds: To identify QTLs that are common across genetic backgrounds, the results of the present study were compared with QTLs for physio-morphological and plant production traits under stress reported in other rice populations. The linkage map developed by McCouch et al $^{[47]}$ served as a bridge to compare maps between different populations. On comparing the locations of the QTLs linked to root traits and plant production traits under drought stress, the genomic region RM3894RG191 on chromosome 3 was found to be significant in terms of drought resistance in Bala $\times$ Azucena RI lines. QTLs for grain yield, days to $50 \%$ flowering, number of productive tillers and leaf drying under stress were mapped in this region in the present study (Fig. 1). Ray et $a .^{[42]}$ reported a QTL for total number of roots in this region in CO39 $\times$ Moroberekan RI lines. Courtois et $a l{ }^{[37]}$ identified QTLs for leaf rolling and leaf drying under stress in the field condition in IR64 $\times$ Azucena DH lines. In the same region, Nguyen et al. ${ }^{[48]}$ and Lanceras et $a l^{[24]}$, respectively identified QTLs for osmotic adjustment and grain yield under drought stress in CT9993 × IR62266 DH lines. Based on the syntenic relationship between maize and rice ${ }^{[25]}$, this QTL segment corresponds to the UMC 11 region of maize chromosome 1. It is interesting to note that the region was also associated with various physiological and agronomic traits in maize i.e., stomatal conductance, root pulling force ${ }^{[22]}$, xylem abscisic acid concentration $^{[50]}$, anthesis-silking interval ${ }^{[51]}$ under drought and other abiotic stress conditions. These results suggested that during cereal evolution, genes in this genomic region in maize and rice might have been conserved to respond to abiotic stresses such as drought ${ }^{[20]}$. G1073 on chromosome 8 was linked to grain yield under stress in this study (Fig. 1). This chromosomal region was linked to osmotic adjustment in CO39 $\times$ Moroberekan RI lines ${ }^{[13]}$ and CT9993 $\times$ IR62266 DH lines ${ }^{[20]}$. Comparative mapping indicates that this region is homoeologus with a segment of wheat chromosome $7 \mathrm{~S}$, where a single locus putatively associated with osmotic adjustment was identified ${ }^{[52]}$. Teulat et al. ${ }^{[53]}$ identified several QTLs for osmotic adjustment related traits on chromosome 1 in barley. This region was homoeologous with the osmotic adjustment QTL region on chromosome 8 in rice. These results suggest that this genomic region may contain a gene or a cluster of genes that confer drought adaptation in many cereals, atleast in barley, rice and wheat ${ }^{[20]}$. Similarly, RG163-RM349 region on chromosome 4 was linked to plant height and days to $50 \%$ flowering under stress in this study. In the same region, Babu et al. ${ }^{[23]}$ and Lanceras et al. ${ }^{[24]}$ identified QTLs for grain yield and spikelet number under drought stress in CT9993 $\times$ IR62266 DH lines. This region was also found to regulate root thickness and total root number in IR64 $\times$ Azucena $\mathrm{DH}^{[19]}$ and $\mathrm{CO} 39$ $\times$ Moroberekan RI lines $^{[42]}$. Thus this genomic region was identified repeatedly as being linked to drought avoidance via deep and thick root system in rice across several genetic backgrounds. The putative QTL RM212-C86 on chromosome 1 identified for plant height and panicle length under stress in the present study was reported to contain QTLs for root pulling force in CT9993 $\times$ IR62266 DH lines ${ }^{[45]}$. This region was shown to affect total root weight and deep root weight in IR $64 \times$ Azucena DH lines ${ }^{[15]}$.

\section{CONCLUSION}

In summary, the rice lines were subjected to severe drought stress during reproductive phase due to a natural rainfall failure event. The RI lines showed significant variation in physio-morphological and plant production traits under stress in TE. QTLs linked to physio-morphological and grain yield under natural drought stress in field condition in TE were identified in rice. Colocation of QTLs for plant production traits under stress and QTLs for various root traits was observed in these rice lines. Consistent QTLs associated with drought resistance traits across genetic backgrounds were detected and may be useful in MAS for rainfed rice improvement. 


\section{ACKNOWLEDGEMENTS}

The research was supported by the Rockefeller Foundation, USA through a grant to Dr. RCB under Food Security program. Thanks to Drs. Abraham Blum and Shu Fukai for their valuable comments on the manuscript.

\section{REFERENCES}

1. IRRI (International Rice Research Institute). 2004. http// www.irri.org

2. IRRI (International Rice Research Institute). 2002. Rice almanac. IRRI-WARDA-CIAT- FAO. Los Banos, Philippines.

3. O'Toole, 1999. Molecular Approaches for the Genetic Improvement of Cereals for Stable Production in Water Limited Environments. In: A Strategic Planning Workshop. (Ed.) Ribaut, J.M. and D. Poland). CIMMYT, El Batan, Mexico.

4. Zeigler, R.S. and D.W. Puckridge, 1995. Improving sustainable productivity in rice based rainfed lowland systems of South and South East Asia. Feeding four billion people. The challenge for rice research in the $21^{\text {st }}$ century. Geo J., 35: 307-324.

5. Ribaut, J.M., C. Jiang, D. Gonzalez-de-Leon, G.O. Edmeades and D.A. Hoisington, 1997. Identification of quantitative trait loci under drought conditions in tropical maize. 2. Yield components and marker-assisted selection strategies. Theor. Appl. Genet., 94: 887-896.

6. Ribaut, J.M, M. Bänziger, T. Setter, G. Edmeades and D. Hoisington, 2004. Genetic Dissection of Drought Tolerance in Maize: A Case Study. In $\mathrm{H}$. Nguyen and A. Blum (ed.) Physiology and Biotechnology Integration for Plant Breeding. Marcel Dekker, Inc. New York

7. Condon, A.G., R.A. Richards, G.J. Rebetzke and G.D. Farquhar, 2004. Breeding for high water use efficiency. J. Exp. Bot., 55: 2447-2460.

8. Sanchez, A.C., P.K. Subudhi, D.T. Rosenow and H.T. Nguyen, 2002. Mapping QTLs associated with drought resistance in sorghum (Sorghum bicolor L. Moench). Plant Mol. Biol. 48 (5-6):713726.

9. Fukai, S. and M. Cooper. 1995. Development of drought-resistant cultivars using physiomorphological traits in rice. Field Crops Res., 40: 67-86.

10. Nguyen, H.T., R.C. Babu and A. Blum, 1997. Breeding for drought resistance in rice: physiology and molecular genetics considerations. Crop Sci. 37:1426-1434.

11. Lafitte, H.R., A. Blum and G. Atlin. 2003. Using secondary traits to identify drought- genotypes tolerant. In: Breeding rice for drought-prone environments. (Ed.) Fischer, K.S., Lafitte, R., Fukai, S., G. Altlin and B. Hardy). IRRI, LasBanos, Philippines, pp: 37-48.
12. Champoux, M.C., G. Wang, S. Sarkarang, D.J. Mackill, J.C. O'Toole, N. Huang and S.R. McCouch, 1995. Locating genes associated with root morphology and drought avoidance in rice via linkage to molecular markers. Theor. Appl. Genet., 90: 961-981.

13. Lilley, J.M., M.M. Ludlow, S.R. McCouch and J.C. O'Toole, 1996. Locating QTL for osmotic adjustment and dehydration tolerance in rice. J. Exp. Bot., 47: 1427-1436.

14. Price, A.H. and A.D. Tomos, 1997. Genetic dissection of root growth in rice (Oryza sativa L.). II: Mapping quantitative trait loci using molecular markers. Theor. Appl. Genet., 95: 143-152.

15. Yadav, R., B. Courtois, N. Huang and G. Mclaren, 1997. Mapping genes controlling root morphology and root distribution in a doubled-haploid population of rice. Theor. Appl. Genet., 94: 619632.

16. Ali, M.L., M.S. Pathan, J. Zhang, G. Bai, S. Sarkarung and H.T. Nguyen, 2000. Mapping QTLs for root traits in a recombinant inbred population from two indica ecotypes in rice. Theor. Appl. Genet., 101: 756-766.

17. Price, A.H., K.A. Steele, B.J. Moore, P.B. Barraclough and L.J. Clark, 2000. A combined RFLP and AFLP map of upland rice (Oryza sativa) used to identify QTL for root-penetration ability. Theor. Appl. Genet., 100: 49-56.

18. Tripathy, J.N., J. Zhang, S. Robin, T.T. Nguyen and H.T. Nguyen, 2000. QTL for cell-membrane stability mapped in rice (Oryza sativa L.). Theor. Appl. Genet., 100: 1197-1202.

19. Zheng, H.G., R.C. Babu, M.S. Pathan, M.L. Ali, N. Huang, B. Courtois and H.T. Nguyen, 2000. Quantitative trait loci for root penetration ability and root thickness in rice: comparison of genetic backgrounds. Genome, 43: 53-61.

20. Zhang, J., H.G. Zheng, A. Aarti, G. Pantuwan, T.T. Nguyen, J.N. Tripathy, A.K. Sarial, S. Robin, R.C. Babu, B.D. Nguyen, S. Sarkarung, A. Blum and H.T. Nguyen, 2001. Locating genomic regions associated with components of drought resistance in rice: Comparative mapping within and across species. Theor. Appl. Genet., 103: 19-29.

21. Li, Z., P. Mu, C. Li, H. Zhang, Z. Li, Y. Gao and $X$. Wang, 2005. QTL mapping of root traits in a doubled haploid population from a cross between upland and lowland japonica rice in three environments. Theor. Appl. Genet., 110: 12441252.

22. Lebreton, C., V. Lazic-Jancic, A. Steed, S. Pekai and S.A. Quarrie, 1995. Identification of QTL for drought responses in maize and their use in testing causal relationships between traits. J. Exp. Bot., 46: 853-865. 
23. Babu, R.C., B.D. Nguyen, V. Chamarek, P. Shanmugasundaram, P. Chezhian, P. Jeyaprakash, S.K. Ganesh, A. Palchamy, S. Sadasivam, S. Sarkarung, L.J. Wade and H.T. Nguyen, 2003. Genetic analysis of drought resistance in rice by molecular markers: association between secondary traits and field performance. Crop Sci., 43: 14571469.

24. Lanceras J.C., G. Pantuwan, J. Boonrat and T. Toojinda. 2004. Quantitative trait loci associated with drought tolerance at reproductive stage in rice. Plant Physiol., 135: 384-399.

25. Zou, G.H., H.W. Mei, H.Y. Liu, G.L. Liu, S.P. Hu, X.Q. Yu, M.S. Li, J.H. Wu and L.J. Luo, 2005. Grain yield responses to moisture regimes in a rice population: association among traits and genetic markers. Theor. Appl. Genet., 00122-005-0111-3.

26. Lafitte, H.R., A.H. Price and B. Courtois, 2004. Yield response to water deficit in an upland rice mapping population: associations among traits and genetic markers. Theor. Appl. Genet., 109:12371246.

27. Babu, R.C., H.E. Shashidhar, J.M. Lilley, N.D. Thanh, J.D. Ray, S. Sadasivam, S. Sarkarang, J.C. O'Toole and H.T. Nguyen, 2001. Variation in root penetration ability, osmotic adjustment and dehydration tolerance among accessions of rice adapted to rainfed lowland and upland ecosystems. Plant Breed., 120: 233-238.

28. Lafitte, H.R. and B. Courtois, 2002. Interpreting cultivar $\times$ environment interactions for yield in upland rice: assigning value to drought adaptive traits. Crop Sci., 42: 1409-1420.

29. IRRI (International Rice Research Institute). 1996. International network for genetic evaluation of rice: Standard evaluation system for rice. IRRI, Los Banos, Philippines.

30. Garrity, D.P. and J.C. O'Toole, 1995. Selection for reproductive stage drought avoidance in rice using infrared thermometry. Agron. J., 87: 773-779.

31. Price, A.H., K.A. Steele, B.J. Moore and R.G.W. Jones. 2002c. Upland rice grown in soil-filled chambers and exposed to contrasting water-deficit regimes II. Mapping quantitative trait loci for root morphology and distribution. Field Crops Res., 76: 25-43.

32. SAS Institute Inc. 1990. SAS/STAT user's guide, Version $6.4^{\text {th }}$ edition, vols 1 and 2. SAS Institute Inc., Cary, North Carolina, USA.

33. Shen, Y.J., H. Jiang, J.P. Jin, Z.B. Zhang, B. Xi, Y.Y. He, G. Wang, C. Wang, L.L Qian, X. Li, Q.B. Yu, H.J. Liu, D.H. Chen, J.H. Gao, H. Huang, T.L. Shi and Z.N. Yang, 2004. Development of genome-wide DNA polymorphism database for map-based cloning of rice genes Plant Physiol., 135: 1198-1205.
34. Basten, C.J., B.S. Weir and Z.B. Zeng, 2001. QTL cartographer 1.15 edn. North Carolina State University.

35. Blum, A., J. Mayer, G. Golan and B. Sinmena, 1999. Drought tolerance of a doubled-haploid line population of rice in the field. In: Genetic improvement of rice for water limited environments. Ito, O. et al (ed.), International Rice Research Institute, Los Banos, Philippines, pp: 319-330.

36. Hemamalini, G.S., H.E. Sashidhar and S. Hittalmani, 2000. Molecular marker assisted tagging of morphological and physiological traits under two contrasting moisture regimes at peak vegetative stage in rice (Oryza sativa L.). Euphytica, 112: 1-10.

37. Courtois, B., G. McLaren, P.K. Sinha, K. Prasad, R. Yadav and L. Shen, 2000. Mapping QTL associated with drought avoidance in upland rice. Mol. Breed., 6: 55-66.

38. Price, A.H., J.E. Cairns, P. Horton, H.G. Jones and H. Griffiths, 2002a. Linking drought-resistance in upland rice using a QTL approach: progress and new opportunities to integrate stomatal and mesophyll responses. J. Expt. Bot., 53: 989-1004.

39. Venuprasad, R., H.E. Shashidhar, S. Hittalmani and G.S. Hemamalini, 2002. Tagging quantitative trait loci associated with grain yield and root morphological traits in rice under contrasting moisture regimes. Euphytica, 128: 293-300.

40. Price, A.H., J. Townend, P.M. Jones, A. Audebert and B. Courtois, 2002b. Mapping QTLs associated with drought avoidance in upland rice grown in the Philippines and West Africa. Plant Mol. Biol., 48: 683-695.

41. Price, A.H., E.M. Young and A.D. Tomos, 1997. Quantitative trait loci associated with stomatal conductance, leaf rolling and heading date mapped in upland rice (Oryza sativa L). New Phytol., 137: 83-91.

42. Ray, J.D., L.X. Yu, S.R. McCouch, M.C. Champoux, G. Wang and H.T. Nguyen, 1996. Mapping quantitative trait loci associated with root penetration ability in rice (Oryza sativa L.). Theor. Appl. Genet., 92: 627-636.

43. Pantuwan, G., S. Fukai, M. Cooper, S. Rajatasereekal and J.C.O. Toole, 2002. Yield response of rice genotypes to different types of drought under rainfed low lands part 1. Grain yield and yield components. Field Crops Res., 73: 153168.

44. Robin, S., M.S. Pathan, B. Courtois, R. Lafitte, S. Carandang, S. Lanceras, M. Amante, H.T. Nguyen and $\mathrm{Z}$. Li, 2003. Mapping osmotic adjustment in an advanced backcross inbred population of rice. Theor. Appl. Genet., 107: 1288-1296. 
45. Zhang, J., H.T. Nguyen and A. Blum, 1999. Genetic analysis of osmotic adjustments in crop plants. J. Exp. Bot., 50: 291-302.

46. Ingram, K., T.F.D. Bueno, O.S. Namuca, E.B. Yambao and C.A. Beyrouty, 1994. Rice root traits for drought resistance and their genetic variation. In: Rice roots: nutrient and water use. Kirk, G. D. (ed.), International Rice Research Institute, Los Banos, Philippines, pp: 67-77.

47. McCouch, S.R., L. Teytelman, Y. Xu, K.B. Lobos, K. Clare, M. Walton, B. Fu, R. Maghirang, Z. Li, Y. Xing, Q. Zhang, I. Kono, M. Yano, R. Fjellstrom, G. Declerck, D. Schneider, S. Cartinhour, D. Ware and L. Stein, 2002. Development and mapping of 2240 new SSR markers for rice. DNA Res., 9: 199-207.

48. Nguyen, T.T.T., N. Klueva, V. Chamareck, A. Aarti, G. Magpantay, A.C.M. Millena, M. S. Pathan and H.T. Nguyen, 2004. Saturation mapping of QTL regions and identification of putative candidate genes for drought tolerance in rice. Mol. Gen. and Genomics, 272: 35-46.

49. Ahn, S. and S.D. Tanksley, 1993. Comparative linkage maps of the rice and maize genomes. Proc. Natl. Acad. Sci. USA, 90: 7980-7984.
50. Tuberosa, R., M.C. Sanguiety, P. Landi, S. Salvi, E. Casarini and S. Conti, 1998. RFLP mapping of quantitative trait loci controlling abscisic acid concentration in leaves of drought stressed maize (Zea mays).Theor. Appl. Genet., 97: 744-755.

51. Ribuat, J.M., D.A. Hoisington, J.A. Deutsch, C. Jiang and D. Gonzalez-de-Leon, 1996. Identification of quantitative trait loci under drought conditions in tropical maize.1.Flowering parameters and the Anthesis-silking interval. Theor. Appl. Genet., 92: 905-914.

52. Morgan, J.M. and M.K Tan, 1996. Chromosomal location of a wheat osmoregulation gene using RFLP analysis. Aust. J. Plant Physiol., 23: 803806.

53. Teulat, B., D. This, M. khairallah, C. Borries, C. Ragot, P. Sourdille, P. Leroy, P. Monneveux and A. Charrier, 1998. Several QTLs involved in osmotic adjustment trait variation in barley (Hordeum vulgare L.) Theor. Appl. Genet., 96: 688-698. 